\title{
TRAF6 regulates the effects of polarized maturation of tolerability: Marrow-derived dendritic cells on collagen-induced arthritis in mice
}

\author{
CHENCHEN ZHUANG, XUEZHI HONG, JIA LIU, XIAOHONG LUO and HANYOU MO \\ Department of Clinical Immunology and Rheumatology, \\ Affiliated Hospital of The Guilin Medical University, Guilin 541004, P.R. China
}

Received November 2, 2016; Accepted December 28, 2016

DOI: $10.3892 /$ br.2017.836

\begin{abstract}
The study aimed to investigate the relationship between tumor necrosis factor receptor-associated factor 6 (TRAF6) and a differentially mature dendritic cell (mDC) in collagen-induced arthritis (CIA) mice and to determine whether or not TRAF6 regulates the activation of an immature dendritic cell (iDC) and inhibits iDC maturation to induce immune tolerance. The mouse bone marrow stem cells were induced with recombinant granulocyte-macrophage colony-stimulating factor (rmGM-CSF) and recombinant interleukin-4 (rmIL-4) to differentiate immature dendritic cells (DCs), which were divided into four groups with different maturation states: rmGM-CSF, rmIL-4; TNF- $\alpha$; LPS; and FK506 group. The levels of the cell surfaces of CD80, CD86, and MHI-II were analyzed by flow cytometry to prove DCs at different levels of maturity. The expression of IL-12 in DCs at different maturation states was detected by enzyme-linked immunosorbent assay (ELISA). The expression of TRAF6 mRNA and protein in each group of DCs was detected by a reverse transcription-polymerase chain reaction (RT-PCR) and western blot analysis. The results revealed that the differentiation of bone marrow cells into iDCs was significantly induced by cytokines (rmGM-CSF, IL-4). CD80, CD86, MHC-II were expressed in the four groups, and the difference between them was statistically significant $(\mathrm{P}<0.05)$. A higher degree of $\mathrm{DC}$ differentiation led to a gradual increase of IL-12 secretion in the four groups. The difference was statistically significant $(\mathrm{P}<0.05)$ for this secretion (group D, 10,620.73 $\pm 276.73 \mathrm{pg} / \mathrm{ml}$ ). The expression levels of TRAF6 mRNA were significantly higher in group $\mathrm{D}$ than those in the other three groups $(\mathrm{P}<0.01)$. Although there was no significant difference in the expression levels of
\end{abstract}

Correspondence to: Dr Hanyou Mo, Department of Clinical Immunology and Rheumatology, Affiliated Hospital of The Guilin Medical University, Guilin 541004, P.R. China

E-mail: mohanyou@hotmail.com

Key words: tumor necrosis factor receptor-associated factor 6, collagen-induced arthritis, dendritic cell maturation, immune tolerance, rheumatoid arthritis
TRAF6 mRNA between groups B and C, the expression levels of TRAF6 mRNA between groups $\mathrm{B}$ and $\mathrm{C}$ were higher than those of the control group. The TRAF6 protein expression was higher in group $\mathrm{D}$ than that in the other three groups $(\mathrm{P}<0.01)$, and the difference was statistically significant. There was a statistically significant difference in the TRAF6 protein expression between group $\mathrm{A}$ and groups $\mathrm{B}$ and $\mathrm{C}$, but the expression in group $\mathrm{C}$ was higher than that in group $\mathrm{B}(\mathrm{P}<0.01)$. In conclusion, the expression of co-stimulatory molecules gradually increased in the DCs of different maturation states, and the expression of IL-12, TRAF6 mRNA, and TRAF6 protein positively correlated with the degree of DC maturation. TRAF6 is important in iDC polarity and maturation.

\section{Introduction}

Rheumatoid arthritis (RA) is associated with T cells and immune cell activation, resulting in joint synovitis. Dendritic cells (DCs) are antigen-presenting cells (APCs) specialized in activating $\mathrm{T}$ cells with a positive or negative immune response $(1,2)$. DCs play different functional roles at different maturation states. The antigen-presenting ability of mature DCs promotes immune response by the activation of $\mathrm{T}$ cells, while that of immature DCs inhibits the activation of $\mathrm{T}$ lymphocytes and activates regulatory $\mathrm{T}$ cells $($ Tregs) $(3,4)$. Immature DCs mediate immune tolerance. Tumor necrosis factor receptor-associated factor 6 (TRAF6) activates TAK1 and NF- $\kappa \mathrm{B}$ molecules in Toll-like receptor (TLR)-signaling pathways, which enter into the nucleus $(5,6)$. To the best of our knowledge, no report has yet established any association between TRAF6 and DC maturation, and that TRAF6 promotes a DC-mediated immune response. We induced DCs at different maturation states to detect TRAF6 expression by cytokines to analyze the correlation between TRAF6 and DCs. Thus, this experiment mainly studied the effect of TRAF6-specific expression on immature dendritic cell (iDC) maturation and the immune tolerance re-establishment.

\section{Materials and methods}

The study was approved by the Ethics Committee of the Guilin Medical University. 
Preparation of the collagen-induced arthritis (CIA) animal model. Fifty 8-week-old male C57 mice, weighing approximately $30 \mathrm{~g}$ were obtained from the Guilin Medical College Experimental Animal Center. Prior to the experiment, chicken type II collagen (including acetic acid with a concentration of $2 \mathrm{mg} / \mathrm{ml}$ ) was added slowly to the same volume of complete Freund's adjuvant (CFA), prepared in sufficient emulsification on ice and the final concentration of the mixture was $1 \mathrm{mg} / \mathrm{ml}$. The C57 mice were immunized intradermally twice at the base of the tail and the back at intervals of 4 weeks, while the normal controls were intragastrically administered with saline. The mice were monitored daily for swelling of limbs for at least 28 days and serum samples were collected at day 7 or 14 after boosting immunity. After the building model was established, the mice that scored $>6$ points in the arthritis index (AI) scoring were used for further testing.

Generation and activation of bone marrow-derived DCs (BMDCs). BMDCs were obtained from the femurs and tibias of the CIA mice, and the red cells were treated with a lysis buffer solution (4.15 g of ammonium chloride per $500 \mathrm{ml}$ of $0.01 \mathrm{M}$ Tris- $\mathrm{HCl}$ buffer). The cells were then washed and cultured in culture flasks at $1 \times 10^{9} \mathrm{cells} / \mathrm{ml}$ in a complete RPMI-1640 culture medium supplemented with $10 \%$ fetal bovine serum (FBS), IL-4 (5,000 U/ml), and GM-CSF $(1,000 \mathrm{U} / \mathrm{ml})$. The culture medium was changed on culture days 3 and 5. New medium and cytokines (GM-CSF and IL-4) were added after rinsing the non-adherent cells. On day 6, any loosely adherent clustered cells were defined as immature BMDCs.

Different maturation stimuli on DCs. DCs were harvested on culture day 6 . Briefly, BMDCs $\left(1 \times 10^{6} /\right.$ well) were seeded in 24-well plates in $1 \mathrm{ml}$ of culture medium and treated with recombinant granulocyte-macrophage colony-stimulating factor (rmGM-CSF). IDCs were induced to DCs at different maturation states according to different methods. The cells were divided into four groups, as follows: group A, the control group was treated with rmGM-CSF and recombinant interleukin-4 (rmIL-4) (rmGM-CSF, rmIL-4 group). Group B, this group was treated with TNF- $\alpha\left(1 \times 10^{6} \mathrm{U} / \mathrm{l}\right)$ (TNF- $\alpha$ group). Group C, this group was treated with LPS (1 mg/l) (LPS group). Group D, this group was treated with rmGM-CSF (10 $\mathrm{ng} / \mathrm{ml})$, FK506 (10 ng/ml), and LPS (1 mg/l) (FK506 group). Each group was then incubated for $24 \mathrm{~h}$.

Flow cytometric analysis of DC phenotypes. The cells were collected on day 7, and washed with PBS. The cells were stained with fluorescence-labeled antibodies (anti-mouse CD11c-APC, CD80-PE, CD86-PE, and MHC-II-PE) for 30 min on ice, washed with FBS, and analyzed via flow cytometry. Data analyses were performed using BD FACSDiva software (Becton-Dickinson, Mountain View, CA, USA). The initially gated cells were further analyzed for CD11c, CD80, CD86, and MHC-II expression.

Different levels of IL-12 secretion by enzyme-linked immunosorbent assay (ELISA). A commercial ELISA kit (PBL Biomedical Laboratories, Piscataway, NJ, USA) was used to

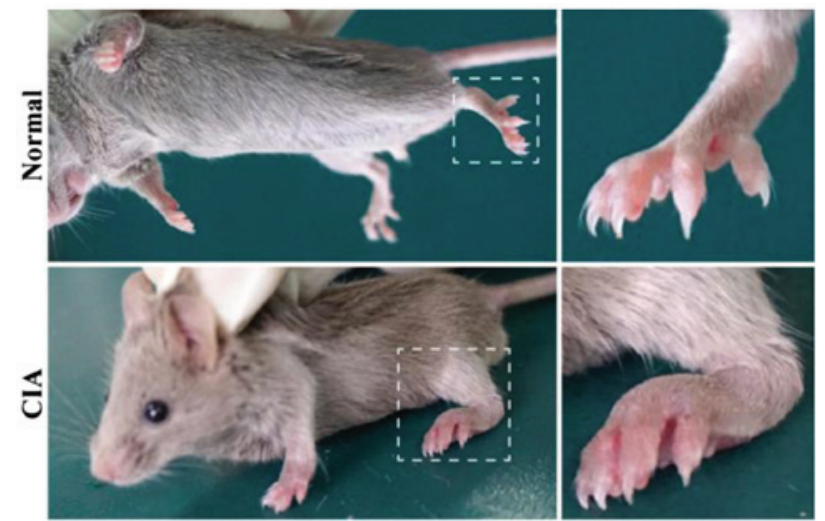

Figure 1. Immunization on day 28: The paws of the CIA mice appeared red and swollen. CIA, collagen-induced arthritis.

measure the serum levels of IL-12 secretion according to the manufacturer's instructions.

Reverse transcription-polymerase chain reaction (RT-PCR). Cells in the logarithmic phase were collected, and then totalRNA was extracted from the cells using TRIzol reagent (Invitrogen, Carlsbad, CA, USA). RNA was quantified using UV absorbance at 260 and $280 \mathrm{~nm}$ (A260/280) by NanoDrop 2000 spectrophotometry (Thermo Fisher Scientific, Waltham, MA, USA). RNA was reverse-transcribed using the BU-Script RT kit (Tiangen Biotech Co., Ltd., Beijing, China) according to the manufacturer's instructions. Primers TRAF6-F (5'-GCC GAA ATG GAA GCA CAG-3') and TRAF6-R (5'-GGG CTA TGG ATG ACA ACA GG-3') were used in conventional PCR detection (Tiangen Biotech Co., Ltd.). The procedures were performed as described elsewhere (7).

Expression of TRAF6 protein by western blot analysis. Total protein from cell lysates was separated by SDS-PAGE and transferred to a nitrocellulose membrane, which was incubated with the 1:200 diluted specific primary antibodies TRAF6 (ab33915, rabbit polyclonal antibody; Abcam, Cambridge, UK) overnight at $4^{\circ} \mathrm{C}$. After incubation with the 1:1,000 diluted HRP-labeled secondary antibody (horseradish peroxidase conjugated goat anti-rabbit immunoglobulin; Abcam) at room temperature for $1 \mathrm{~h}$, the membranes were developed with enhanced chemiluminescence (ECL) detection system (Gel Logic 2200 PRO; Kodak, Tokyo, Japan).

Statistical analysis. SPSS 17.0 statistical software (SPSS Inc., Chicago, IL, USA) was used to conduct analyses. Data were presented as means \pm SD to indicate single factor variance. Comparisons were made using one-way ANOVA. The differences were considered significant when $\mathrm{P}<0.05$.

\section{Results}

CIA induction. A boost injection of equal collagen-IFA suspension was given in the same manner on day 21. The experimental group with 50 C57 mice had 40 mice successfully modeling CIA (4/5). Clinical symptoms of CIA started to occur around day 28 after the primary immunization, including joint swelling and joint deformity (Fig. 1). 
Table I. Expression of the co-stimulatory molecules in the four groups of DCs.

\begin{tabular}{lrrr}
\hline Group & \multicolumn{1}{c}{ CD80 } & \multicolumn{1}{c}{ CD86 } & \multicolumn{1}{c}{ MHC-II } \\
\hline A & $9.06 \pm 0.58$ & $12.32 \pm 0.62$ & $8.36 \pm 0.62$ \\
B & $11.06 \pm 0.68$ & $18.65 \pm 0.83$ & $9.23 \pm 0.61$ \\
C & $14.67 \pm 0.74$ & $30.37 \pm 1.37$ & $14.28 \pm 0.60$ \\
D & $19.01 \pm 0.92$ & $69.55 \pm 0.96$ & $18.19 \pm 0.96$ \\
\hline
\end{tabular}

The difference among the four groups was statistically significant $(\mathrm{P}<0.05)$. DCs, dendritic cells.

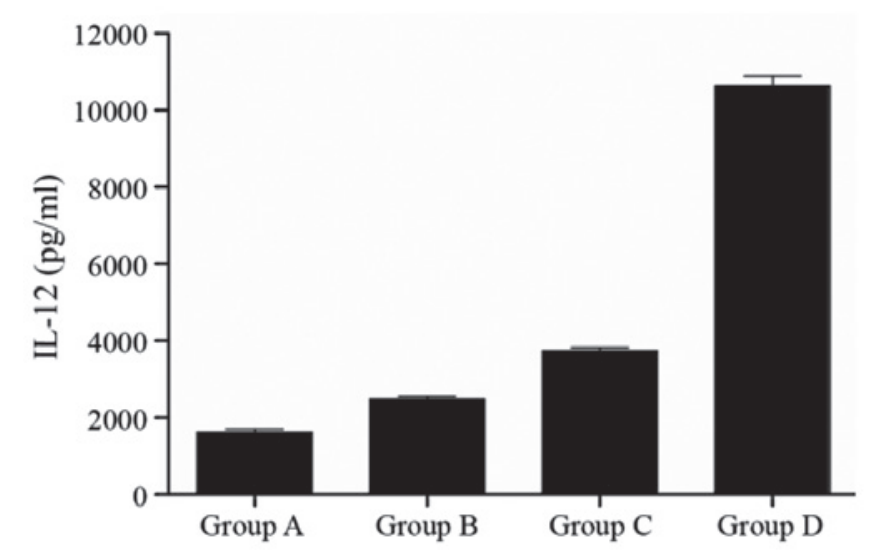

Figure 2. Expression of IL-12 in the four groups of DCs. DCs, dendritic cells.

DC cultures. Bone marrow cells of the C57 mice were induced to differentiate the BMDCs by cytokines rmGM-CSF and rmIL-4. Flow cytometric identification of CD11c DCs was $>70 \%$.

Changes in the expression of DC maturation. To analyze the expression of the co-stimulatory molecules (i.e., CD80, CD86, and MHC-II) from differentially matured DCs in the experimental groups, the results show that there is an increasing trend in the expression of the co-stimulatory molecules among the four groups (Table I), and the difference was statistically significant $(\mathrm{P}<0.05)$. The expression of $\mathrm{CD} 86$ in group $\mathrm{D}$ was higher than that in the other three groups (mean 69.55 \pm 2.26 ). The results suggested that group D demonstrated highly increased levels of DC maturation.

IL-12 expression by DCs at different matured states. The supernatants from the four groups were harvested and analyzed by ELISA. The concentration of each group was calculated from OD readings using a standard curve. The values were as follows: group A, 1,623.35 $\pm 83.32 \mathrm{pg} / \mathrm{ml}$; group B, $2,486.14 \pm 65.26 \mathrm{pg} / \mathrm{ml}$; group C, $3,742.58 \pm 87.16 \mathrm{pg} / \mathrm{ml}$; and group D, $10,620.73 \pm 276.73 \mathrm{pg} / \mathrm{ml}$ (Fig. 2). There was a significant difference in each group $(\mathrm{P}<0.05)$.

mRNA-TRAF6 by pulsed-field gel electrophoresis (PFGE). The expression of mRNA-TRAF6 in group D was superior to that of the three other groups $(\mathrm{P}<0.01)$. The level of
$\mathbf{A}$
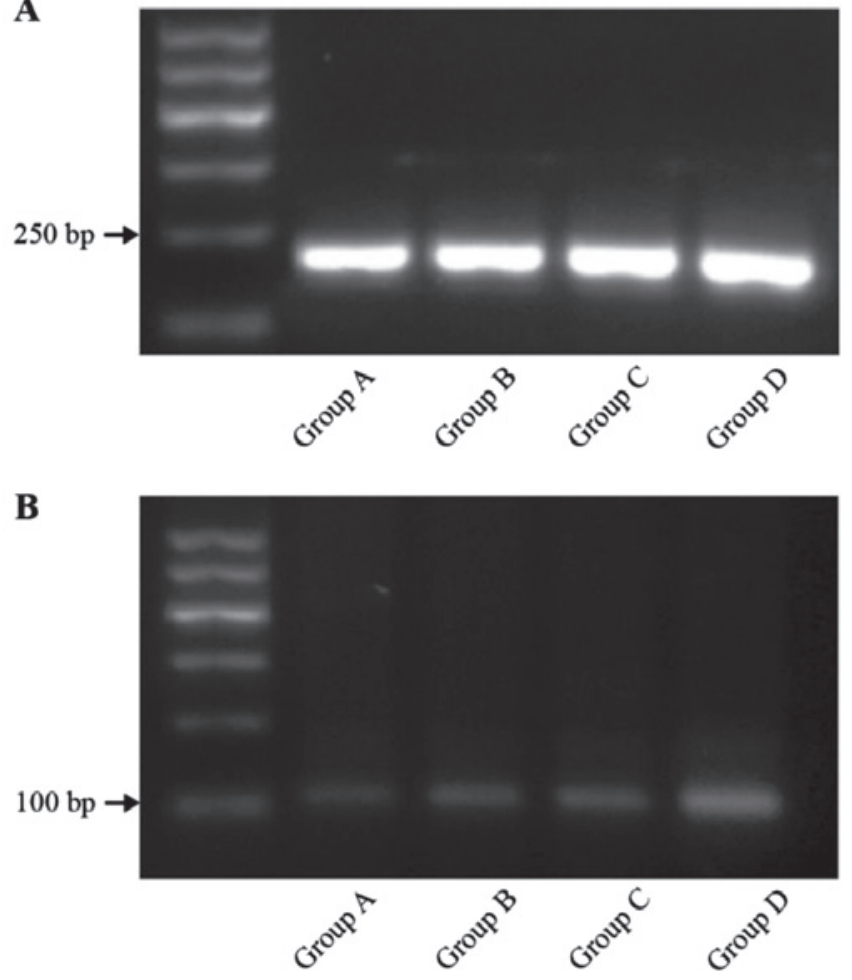

Figure 3. Expression of RNA-TRAF6 in the groups of DCs. TRAF6, tumor necrosis factor receptor-associated factor 6; DCs, dendritic cells.

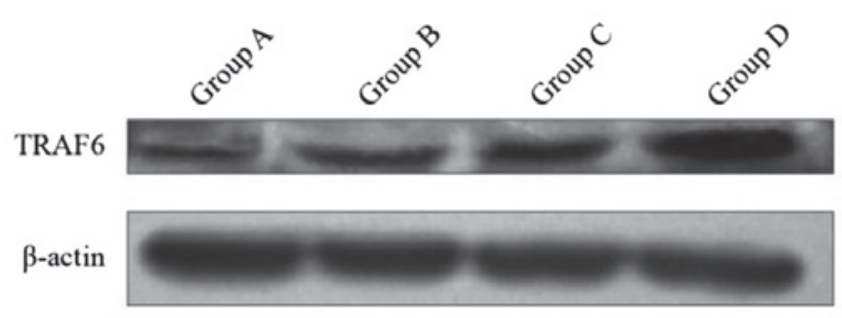

Figure 4. Expression of RNA-TRAF6 in the groups of DCs. TRAF6, tumor necrosis factor receptor-associated factor 6; DCs, dendritic cells.

mRNA-TRAF6 expression in groups B and C was higher than that in the control group $(\mathrm{P}<0.01)$. The results were as follows: group A, $0.046 \pm 0.007$; group B, $0.063 \pm 0.006$; group C, $0.062 \pm 0.006$; and group D, $0.151 \pm 0.08$ (Fig. 3).

Expression of protein TRAF6 in DCs. The expression of protein TRAF6 in group D was superior to the three other groups by inducing DC at different maturation states. The differences were statistically significant $(P<0.01)$. The difference between groups B and C, and group A was statistically significant $(\mathrm{P}<0.01)$ (Fig. 4). The results in the four groups were as follows: group A, $0.49 \pm 0.006$; group B, $0.65 \pm 0.005$; group C, $0.75 \pm 0.005$; and group D, $1.15 \pm 0.003$.

\section{Discussion}

RA is a systemic, inflammatory, autoimmune disorder. However, the exact mechanism has yet to be fully clarified. Most scholars believe that the pathogenesis of RA may be 
caused by chronic inflammation of synovial tissue. During the onset of RA, an acute inflammation of the synovial lining (synovitis) leads to an extensive expansion of the corresponding cells (i.e., pannus formation and inflammatory cytokines), massive infiltration of leukocytes of the innate immune system (i.e., T and B cells, plasmocytes, and macrophages), and synovial fibroblast proliferation (8-10). The latter are regarded as effector cells responsible for cartilage and bone destruction in RA. Then, RA leads to deformity and evenutally to significant functional decline $(11,12)$.

Following in-depth study of the pathogenesis of RA, most scholars agree that the abnormalities of autoreactive $\mathrm{T}$ cells induced by antigen-presenting cells (APCs) are the central link in the pathogenesis of RA (13-15). DCs are the most powerful APCs and play an important role in the abnormal activation of T cells and the occurrence and development of RA. DCs present a two-way immune regulation: i) Ability to capture, process, and present exogenous antigens leading to $\mathrm{T}$-cell differentiation and immune response; and ii) ability of DC to trigger an effective T-cell response and production of self- and foreign antigens. Thus, DCs are important in sustaining the central and peripheral immune tolerance (16-19).

Recent studies found that TLRs are crucial cellular sentinels used to detect 'danger' signals released in DCs and may be important initiators of DC maturation and activation. TRAF6 is a key to TLR activation and intersecting signaling pathways activated the NF- $\mathrm{NB}$ and mitogen-activated protein kinase pathways. TRAF6 assists in the maturity of DC-mediated signal transduction and is a key to DC formation, activation, and maturation (20-22). Thus, to explore specific interventions of TRAF6 expression is essential, which inhibits DC maturation, reconstructs RA immune tolerance, and plays a therapeutic role $(23,24)$.

We found that DCs derived from mouse bone marrow and different methods stimulated differentiation and maturation of DCs. Expression of co-stimulatory molecules (i.e., CD80 and CD86) increased in the mature DC, enhanced the ability of antigen presentation, and decreased antigen uptake. The highest maturity degree of DCs is CD86 expression, while in the experiments IL-12 is produced mainly by DCs, macrophages, and B lymphocytes. The increased secretion of IL-12 into the supernatants was altered with the increase of maturity degree, which is consistent with previous literature $(25,26)$. The present findings have shown that the TRAF6 gene and protein expression were correlated with DC maturity, which showed an increasing trend. Among the most obvious was the cocktail method. Some studies found that under appropriate stimulation conditions, DCs with a TRAF6 gene defect failed to upregulate co-stimulatory molecules (i.e., CD80 and CD86), MHC, and release of pro-inflammatory cytokines and did not activate T cell-mediated immune responses (27). Those results are consistent with our findings, which show that TRAF6 plays an important role in DC differentiation and maturation.

Previous results showed that no or a low expression of co-stimulatory molecules was detected in immature DCs by mediating immune clearance, immune incompetent, and Treg cell induction. Thus, the iDCs induced peripheral immune tolerance, maintained immune balance, and inhibited autoimmunity disease. The study found that there was an increasing trend for DCs in different maturation states with increasing TRAF6 expression Thus, we inhibited the expression of TRAF6 in DCs, which reduced the Toll-TRAF6 NF- $\kappa$ B signaling pathway, maintained DCs in an immature state, and decreased the release of pro-inflammatory cytokines (i.e., IL-1, IL-6, IL-12, and TNF- $\alpha$ ). It is expected that the immune tolerance may be re-established through the intervention of TRAF6 expression. This study has clearly shown that TRAF6 regulates the differentiation and maturation of DCs in animal experiments. Thus, TRAF6 should be evaluated as a potential target for clinical therapy.

\section{Acknowledgements}

Te present study was supported by grants from the Chinese National Natural Science Foundation (no. 81360462) and the Guangxi Natural Science Foundation (no. 2013GXNSFAA019111).

\section{References}

1. Church LD, Filer AD, Hidalgo E, Howlett KA, Thomas AM, Rapecki S, Scheel-Toellner D, Buckley CD and Raza K: Rheumatoid synovial fluid interleukin-17-producing CD4 T cells have abundant tumor necrosis factor-alpha co-expression, but little interleukin-22 and interleukin-23R expression. Arthritis Res Ther 12: R184, 2010.

2. E XQ, Meng HX, Cao Y, Zhang SQ, Bi ZG and Yamakawa M: Distribution of regulatory $\mathrm{T}$ cells and interaction with dendritic cells in the synovium of rheumatoid arthritis. Scand J Rheumatol 41: 413-420, 2012.

3. Lee HW, Kim TS, Kang YJ, Kim JY, Lee S, Lee WJ and Sohn Y: Up-regulated S100 calcium binding protein A8 in Plasmodium-infected patients correlates with $\mathrm{CD} 44^{+} \mathrm{CD} 25^{+} \mathrm{Foxp} 3$ regulatory T cell generation. Malar J 14: 385, 2015.

4. Ferraccioli G and Zizzo G: The potential role of Th17 in mediating the transition from acute to chronic autoimmune inflammation: Rheumatoid arthritis as a model. Discov Med 11: 413-424, 2011.

5. Guo M, James AW, Kwak JH, Shen J, Yokoyama KK, Ting K, Soo CB and Chiu RH: Cyclophilin A (CypA) plays dual roles in regulation of bone anabolism and resorption. Sci Rep 6: 22378, 2016.

6. Hontelez S, Ansems M, Karthaus N, Zuidscherwoude M, Looman MW, Triantis V and Adema GJ: Dendritic cell-specific transcript: Dendritic cell marker and regulator of TLR-induced cytokine production. J Immunol 189: 138-145, 2012.

7. Zhu M, Mo H, Li D, Luo X and Zhang L: Th17/Treg imbalanceinduced by increased incidence of atherosclerosis in patients with Systemic Lupus Erythematosus (SLE). Clinical Rheumatology 32: 1045-52, 2013.

8. Zhang L, Xu Y, Shen J, He F, Zhang D, Chen Z, Duan Y and Sun J: Feasibility study of DCs/CIKs combined with thoracic radiotherapy for patients with locally advanced or metastatic non-small-cell lung cancer. Radiat Oncol 11: 60, 2016.

9. Salmon H, Idoyaga J, Rahman A, Leboeuf M, Remark R, Jordan S, Casanova-Acebes M, Khudoynazarova M, Agudo J, Tung N, et al: Expansion and activation of CD103(+) dendritic cell progenitors at the tumor site enhances tumor responses to therapeutic PD-L1 and BRAF inhibition. Immunity 44: 924-938, 2016.

10. Kao JY,Zhang M, Miller MJ, Mills JC, Wang B, Liu M, Eaton KA, Zou W, Berndt BE, Cole TS, et al: Helicobacter pylori immune escape is mediated by dendritic cell-induced Treg skewing and Th17 suppression in mice. Gastroenterology 138: 1046-1054, 2010.

11. Jalil SF, Arshad M, Bhatti A, Ahmad J, Akbar F, Ali S and John P: Rheumatoid arthritis: What have we learned about the causing factors? Pak J Pharm Sci 29: 629-645, 2016.

12. Wehmeyer C, Frank S, Beckmann D, Böttcher M, Cromme C, König U, Fennen M, Held A, Paruzel P, Hartmann C, et al: Sclerostin inhibition promotes TNF-dependent inflammatory joint destruction. Sci Transl Med 8: 330ra35, 2016. 
13. Simmons DP, Wearsch PA, Canaday DH, Meyerson HJ, Liu YC, Wang Y, Boom WH and Harding CV: Type I IFN drives a distinctive dendritic cell maturation phenotype that allows continued class II MHC synthesis and antigen processing. J Immunol 188: 3116-3126, 2012.

14. Popa C, van Lieshout AW, Roelofs MF, Geurts-Moespot A, van Riel PL, Calandra T, Sweep FC and Radstake TR: MIF production by dendritic cells is differentially regulated by Toll-like receptors and increased during rheumatoid arthritis. Cytokine 36: 51-56, 2006.

15. Sabatté J, Maggini J, Nahmod K, Amaral MM, Martínez D, Salamone G, Ceballos A, Giordano M, Vermeulen M and Geffner J: Interplay of pathogens, cytokines and other stress signals in the regulation of dendritic cell function. Cytokine Growth Factor Rev 18: 5-17, 2007.

16. Snir O, Rieck M, Gebe JA, Yue BB, Rawlings CA, Nepom G, Malmström V and Buckner JH: Identification and functional characterization of $\mathrm{T}$ cells reactive to citrullinated vimentin in HLA-DRB $1 * 0401$-positive humanized mice and rheumatoid arthritis patients. Arthritis Rheum 63: 2873-2883, 2011

17. Wu H, Chen J, Song S, Yuan P, Liu L, Zhang Y, Zhou A, Chang Y, Zhang $L$ and Wei $W$ : $\beta 2$-adrenoceptor signaling reduction in dendritic cells is involved in the inflammatory response in adjuvant-induced arthritic rats. Sci Rep 6: 24548, 2016.

18. Tucci M, Stucci S, Savonarola A, Ciavarella S, Cafforio P, Dammacco F and Silvestris F: Immature dendritic cells in multiple myeloma are prone to osteoclast-like differentiation through interleukin-17A stimulation. Br J Haematol 161: 821-831, 2013.

19. Kaisho T, Hoshino K, Iwabe T, Takeuchi O, Yasui T and Akira S Endotoxin can induce MyD88-deficient dendritic cells to support T(h) 2 cell differentiation. Int Immunol 14: 695-700, 2002.

20. Tamaki Y, Takakubo Y, Hirayama T, Konttinen YT, Goodman SB, Yamakawa M and Takagi M: Expression of Toll-like receptors and their signaling pathways in rheumatoid synovitis. J Rheumatol 38: 810-820, 2011.
21. Kobayashi T, Walsh PT, Walsh MC, Speirs KM, Chiffoleau E, King CG, Hancock WW, Caamano JH, Hunter CA, Scott P, et al: TRAF6 is a critical factor for dendritic cell maturation and development. Immunity 19: 353-363, 2003.

22. Li M, Wang J, Fang Y, Gong S, Li M, Wu M, Lai X, Zeng G, Wang Y, Yang K, et al: MicroRNA-146a promotes mycobacterial survival in macrophages through suppressing nitric oxide production. Sci Rep 6: 23351, 2016.

23. Varney ME, Niederkorn M, Konno H, Matsumura T, Gohda J, Yoshida N, Akiyama T, Christie S, Fang J, Miller D, et al: Loss of Tifab, a del(5q) MDS gene, alters hematopoiesis through derepression of Toll-like receptor-TRAF6 signaling. J Exp Med 212: 1967-1985, 2015.

24. Wang H, Chen W, Wang L, Li F, Zhang C and Xu L: Tumor necrosis factor receptor-associated factor 6 promotes migration of rheumatoid arthritis fibroblast-like synoviocytes. Mol Med Rep 11: 2761-2766, 2015.

25. Arellano-Orden E, Calero-Acuña C, Moreno-Mata N, Gómez-Izquierdo L, Sánchez-López V, López-Ramírez C, TobarD,López-Villalobos JL, Gutiérrez C,Blanco-Orozco A, etal: Cigarette smoke decreases the maturation of lung myeloid dendritic cells. PLoS One 11: e0152737, 2016.

26. Colletti NJ, Liu H, Gower AC, Alekseyev YO, Arendt CW and Shaw MH: TLR3 signaling promotes the induction of unique human BDCA-3 dendritic cell populations. Front Immunol 7: 88, 2016.

27. Walsh MC, Lee JE and Choi Y: Tumor necrosis factor receptorassociated factor 6 (TRAF6) regulation of development, function, and homeostasis of the immune system. Immunological Reviews 266: 72-92, 2015. 